\title{
Consensual predictions of potential distributional areas for invasive species: a case study of Argentine ants in the Iberian Peninsula
}

\author{
Núria Roura-Pascual · Lluís Brotons · \\ A. Townsend Peterson · Wilfried Thuiller
}

Received: 28 August 2007/ Accepted: 10 June 2008/Published online: 27 June 2008

(C) Springer Science+Business Media B.V. 2008

\begin{abstract}
Invasive species are known to influence the structure and function of invaded ecological communities, and preventive measures appear to be the most efficient means of controlling these effects. However, management of biological invasions requires use of adequate tools to understand and predict invasion patterns in recently introduced areas. The present study: (1) estimates the potential geographic distribution and ecological requirements of the Argentine ant (Linepithema humile Mayr), one of the most
\end{abstract}

N. Roura-Pascual

Departament de Ciències Ambientals, Universitat de Girona, Campus de Montilivi, 17071 Girona, Catalonia, Spain

N. Roura-Pascual ( $\square)$

Centre for Invasion Biology, Department of Botany and Zoology, Stellenbosch University, Private Bag X1, Matieland 7602, South Africa

e-mail: nrourapascual@gmail.com

L. Brotons

Àrea de Biodiversitat, Centre Tecnològic Forestal de Catalunya, Pujada del Seminari s/n, 25280 Solsona, Spain

\section{A. T. Peterson}

Natural History Museum and Biodiversity Research Center, The University of Kansas, Lawrence, KS 66045, USA

\section{W. Thuiller}

Laboratoire d'Ecologie Alpine, UMR-CNRS 5553, Université J. Fourier, BP 53, 38041 Grenoble Cedex 9, France conspicuous invasive species throughout the world, in the Iberian Peninsula using ecological niche modeling, and (2) provides new insights into the process of selection of consensual areas among predictions from several modeling methodologies. Ecological niche models were developed using 5 modeling techniques: generalized linear models (GLM), generalized additive models (GAM), generalized boosted models (GBM), Genetic Algorithm for Rule-Set Prediction (GARP), and Maximum Entropy (Maxent). Models for the eastern and western portions of the Iberian Peninsula were built using subsets of occurrence and environmental data to investigate the potential for ecological niche differences between the invading populations. Our results indicate geographic differences between predictions of different approaches, and the utility of ensemble predictions in identifying areas of uncertainty regarding the species' invasive potential. More generally, our models predict coastal areas and major river corridors as highly suitable for Argentine ants, and indicate that western and eastern Iberian Peninsula populations occupy similar environmental conditions.

Keywords Biological invasions .

Consensual areas - Ecological differences .

Genetic Algorithm for Rule-Set Prediction (GARP) . Generalized additive models (GAM) .

Generalized boosted models (GBM) .

Generalized linear models (GLM) .

Iberian Peninsula - Invasive ants .

Linepithema humile $\cdot$ Maximum Entropy (Maxent) 


\section{Introduction}

Rates of species' introductions are increasing globally as a consequence of broadening human movements (Vitousek et al. 1997). This invasive presence frequently has negative influences on native communities and ecosystems, with consequences such as species loss, food web reorganization, community simplification, and changes in disturbance regimes (Chapin et al. 2000; Mack et al. 2000). As such, techniques for modeling species' potential distributions could support pro-active strategies to avoid the introduction or to guide screening to impede establishment of invasive alien species (Peterson 2003; Drake and Lodge 2006).

A highly successful invasive species is the Argentine ant (Linepithema humile). Native to the Río de la Plata region in South America (Tsutsui et al. 2001; Wild 2004), Argentine ants are now established in many Mediterranean-type and subtropical areas worldwide (Suarez et al. 2001). With the development of global trade, Argentine ants have been transported on a large scale to new areas associated with humans (Suarez et al. 2001; Ward et al. 2005), from where they invade natural habitats, causing severe ecologic and economic impacts (Vega and Rust 2001). In the Iberian Peninsula, at least two points of introduction have been detected: first observations date to 1894 in Oporto (western Iberian Peninsula), and to 1923 or possibly 1919 in Valencia (eastern Iberian Peninsula) (Espadaler and Gómez 2003). Presently, Argentine ants range along much of the coastal zone, except along the Cantabrian coast where records are scarce. Few populations are known from interior localities, except those associated with urban centers (Espadaler and Gómez 2003; Carpintero et al. 2004). Several studies have analyzed Argentine ant invasion in the region (Way et al. 1997; Espadaler and Gómez 2003; RouraPascual et al. 2004; Carpintero et al. 2005; RouraPascual et al. 2006; Carpintero and Reyes-López 2008), but none has focused on regional-scale ecological requirements of the species in this part of its introduced range.

Species' distribution patterns are eminently scaledependent, since different ecological processes emerge depending on the spatial scale of analysis (Wiens 1989; Mackey and Lindenmayer 2001; Farina et al. 2005). Distributional patterns of Argentine ants have been studied at both large (Roura-Pascual et al. 2004; Hartley et al. 2006; Roura-Pascual et al. 2006) and small (Hartley and Lester 2003; Krushelnycky et al. 2005) spatial scales. Here, we analyze the Argentine ant distribution at regional scales using ecological niche modeling to elucidate the main factors responsible for its present-day distribution across the Iberian Peninsula.

With the increasing use and improvement of ecological niche models in the last few decades (Guisan and Thuiller 2005; Araújo and Guisan 2006; Elith et al. 2006), it has become clear that predictions are sensitive not only to occurrence and environmental data, but also to the methods used to calibrate the models (Thuiller 2004; Pearson et al. 2006). Elith et al. (2006) have demonstrated differences in predictive performance among modeling methods, as well as significant variations among regional datasets. To deal with this variability, one solution is to develop models using multiple modeling methods and to identify consensual areas of consistent prediction (e.g., Anderson et al. (2003); Araújo et al. (2006)). Areas of consensus among predictions incorporate modeling uncertainties to produce more reliable estimates of species' potential distributions (Hartley et al. 2006). For this reason, we have developed ensemble models across modeling approaches for determining the potential distribution of Argentine ants in the Iberian Peninsula.

In addition, variations in occurrence and environmental data have long been known to produce divergences among geographic predictions. Models calibrated based on a wider range of environmental conditions are better able to outline ecological niches of species than models developed using restricted geographic areas and subsets of data, which tend to predict narrower suitable areas for the species. Hence, we also modeled potential distributions of Argentine ants based on the eastern and western sides of the Iberian Peninsula separately. The two sides present different colonization histories (Giraud et al. 2002) and ecological characteristics (Mediterranean versus Atlantic influences, respectively), which could produce divergences in invasion patterns of Argentine ants in the Iberian Peninsula. Hence, we had two objectives: (1) to determine the potential distribution of Argentine ants in the Iberian Peninsula and the environmental factors that explain the present-day occurrence of the species at regional spatial scales, and (2) to study possible divergences in the invasive process among populations within the Iberian Peninsula. 


\section{Materials and methods}

The approach used herein is based on modeling species' ecological niches, here taken as the set of conditions under which a species is able to persist and maintain stable populations without immigrational subsidy (Grinnell 1917; Hutchinson 1957). Niche modeling algorithms search for non-random associations between known occurrences of the species and relevant ecological/environmental parameters in the form of digital maps; these niche models are then used to identify areas fitting the ecological requirements of the species (Soberón and Peterson 2005). A limitation, however, is when the ecological characteristics of species' present distributions do not reflect their entire ecological potential, because this ecological diversity is not fully represented on that landscape, or the species is not in equilibrium. Despite this limitation, niche models based on occurrence data from native or introduced ranges can potentially indicate some, although not all, new areas susceptible to invasion, and can elucidate ecological processes governing invasion processes (Peterson 2003).

In contrast to previous studies predicting the potential distribution of the Argentine ant in introduced areas based on occurrence data from the native area (Roura-Pascual et al. 2004; Hartley et al. 2006), we only use occurrence data from the invaded range to calibrate the models. Although Argentine ants are not known to be in equilibrium with the environment (Casellas 2004) and models might thus underestimate its potential distribution, we think that the current distribution of the species in the region provides a good estimate of its potential range based on two main facts. Firstly, we did not find significant differences in model performance between predictions derived from models calibrated using native and invaded occurrences (Roura-Pascual et al. 2006). Secondly, since the first observations were made approximately 100 years ago, the species has had time to sample a wide variety of available habitats. Based on these considerations, we preferred to use occurrence data from the invaded range to understand in great detail the main drivers of the Argentine ant invasion in the Iberian Peninsula.

\section{Occurrence and environmental datasets}

We used 350 known occurrence localities for Argentine ants across the Iberian Peninsula compiled from

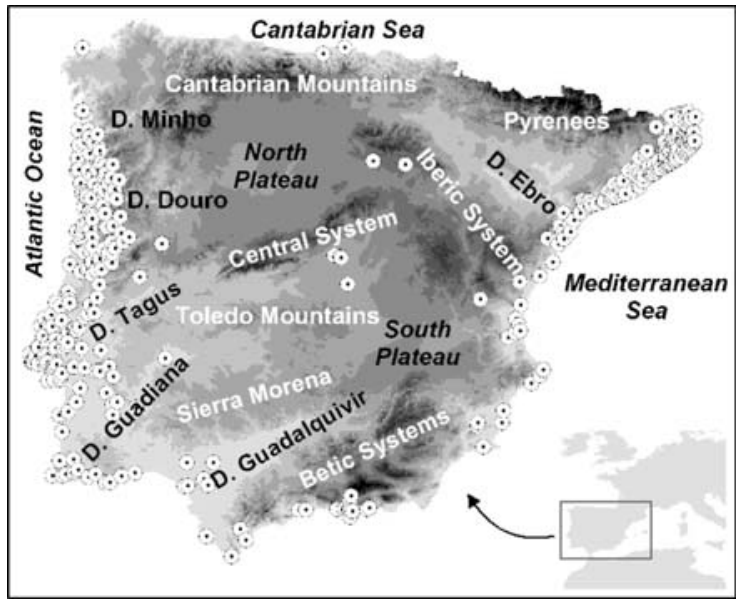

Fig. 1 Distribution of the Argentine ant in the Iberian Peninsula (SW Europe), with known occurrences indicated as dots. Darker shades indicate higher elevations

specimens at natural history museums and personal collections, scientific literature, and field surveys (full dataset provided as electronic appendices in RouraPascual et al. (2004)) (Fig. 1). Since absence data were unavailable, we generated pseudoabsence data for constructing the models despite being aware of their limitations (Brotons et al. 2004; Pearce and Boyce 2006).

To summarize the environmental space potentially available to Argentine ants, we used 12 coverages summarizing aspects of topography ${ }^{1}$ (elevation (herein abbreviated as elev), orientation (orient), and slope (slope), derived from the $200 \mathrm{~m}$ resolution digital elevation model of the Iberian Peninsula, Ninyerola et al. 2005); and climate $^{2}$ (annual mean solar radiation (amrad), annual mean precipitation (amprecip), annual mean temperatures (amtemp), minimum winter mean temperatures (minwtemp), and maximum summer mean temperatures (maxstemp), from the $200 \mathrm{~m}$ resolution Digital Climatic Atlas of the Iberian Peninsula, Ninyerola et al. 2005); and remotely sensed data $^{3}$ (16-day composites at $500 \mathrm{~m}$ for the Normalized Difference Vegetation Index $(N D V I)$ and for the Enhanced Vegetation Index $(E V I)$ from July 2005 from the NASA-MODIS/Terra

\footnotetext{
$\overline{1}$ http://opengis.uab.es/wms/iberia/index.htm

2 Ibid. http://opengis.uab.es/wms/iberia/catala/ca_bibliografia. htm

3 http://edcimswww.cr.usgs.gov
} 
dataset, Justice et al. 1998). These environmental data were selected according to our knowledge of the species' ecology (Holway et al. 2002; Abril 2005; Krushelnycky et al. 2005; Heller et al. 2006; Menke and Holway 2006; Menke et al. 2007; Heller et al. 2008). Minimum winter mean temperatures were obtained by calculating the mean of December, January, February, and March minimum temperatures, and maximum summer mean temperatures by calculating the mean of May, June, July, August, September, and October maximum temperatures. Months were selected according to known details of Argentine ant activity; the period May-October is when the species is most active. We also used NDVI/ EVI 16-day composites from July because during this month the Argentine ant is most active (Abril 2005). All data were resampled to $600 \mathrm{~m}$ spatial resolution for analysis.

Ecological niche modeling techniques

Five different modeling methods were used to produce ensemble predictions. The first two methods, generalized linear models (GLM) and generalized additive models (GAM), are generalizations of classical linear regression models that have been used widely to model, explain, and predict species' distributions (Guisan et al. 2002). GLM allows for non-linearity and non-constant variance among data, whereas GAM permits non-parametric and complex relationships between the response and predictor variables, in addition to parametric forms (Hastie and Tibshirani 1990; Guisan et al. 2002). In GLM, predictor variables (i.e., the environmental data) are combined to generate linear, quadratic, and cubic parametric terms related to the expected value of the response variable (i.e., probability of presence versus absence of the species) through a logit link function (Guisan et al. 2002; Rushton et al. 2004). Although widely applied in ecological studies, GLM has difficulties in dealing with complex ecological relationships (Elith et al. 2006). By fitting nonparametric, smoothed functions of explanatory variables to the response variable without prejudging the shape of the relationship between both terms, GAM produces more flexible response curves than most classical linear models. In both GLM and GAM, the most influential variables and the required transformation (polynomial terms and degree of smoothness, respectively) were selected through a stepwise procedure based on the AIC criterion (Akaike 1974).

We also applied a recent proposed alternative, the generalized boosted model (GBM) (Friedman 2001). Contrary to previous methods that produce single parsimonious models, GBM uses an iterative method (the boosting algorithm) for developing multiple regression trees and combining them into an ensemble prediction (Friedman and Meulman 2003). "Regression trees" are built by splitting the calibration data repeatedly, according to a simple rule based on a single explanatory variable. At each split, the data are partitioned into two exclusive groups, each of which is as homogeneous as possible. The heterogeneity of a node is defined with a deviance notion that can be interpreted as the deviance of a multinomial model (Breiman et al. 1984). Regression trees have been used successfully in ecology (Rouget et al. 2001; Thuiller et al. 2003). "Boosting" is used to overcome the inaccuracies of a single model (see discussion in (Araújo and New (2007)), and makes possible to model a complex response surface. For more details or applications in ecology, see Ridgeway (1999); Friedman (2001); Elith et al. (2006); Leathwick et al. (2006); Elith et al. (2008).

Although these three above-mentioned methods have been usually used with presence-absence data, they can be applied to presence-only situations by using pseudo-absence selected randomly from areas from which the species is not known (Brotons et al. 2004; Pearce and Boyce 2006). Herein, to calibrate final models, we generated an equal number of pseudo-absences as presence localities by selecting a random subset of pixels from the overall study area. All of these modeling techniques were run under the BIOMOD modeling application (Thuiller 2003) or RCRAN software, which relies on the use of GLM, GAM (by T. Hastie) and GBM (by G. Ridgeway) libraries.

In contrast to this group of modeling methods, we also implemented two evolutionary-computing methods that generate pseudo-absences as an intrinsic step in the modeling algorithm, GARP and Maxent. Although they are not considered presence-only methods, these two techniques have been proved to outperform classical presence-only models assessing the distribution of species (Elith et al. 2006; Ward 2007). The Genetic Algorithm for Rule-Set 
Prediction (GARP) uses different rule types (logistic regression, range rules, negated range rules, and atomic rules) to develop a rule-set defining the species' ecological niche (Stockwell and Noble 1992; Stockwell and Peters 1999), which is projected into geographic space to produce a binary map of presence versus absence. The model evolves through an iterative process of rule selection, evaluation, testing and incorporation or rejection, randomly subsetting occurrence data into training and testing data to estimate the predictive accuracy of each rule (here 50\% and 50\%, respectively). Then, input training presence data are resampled randomly with replacement to create a set of 1,250 presence points, and an equal number of points is also resampled randomly from the background area where the species has not been recorded (pseudoabsences). Change in predictive accuracy between iterations is used to evaluate whether particular rules should be incorporated into the model; the algorithm runs 1,000 iterations or until convergence. To optimize model performance, we developed 100 replicate GARP models and chose a "best subset" of 10 models based on error distributions for individual models (Anderson et al. 2003), which were summed to provide an estimate of potential distribution for Argentine ant.

Finally, the Maximum Entropy method (Maxent) is a machine-learning method that uses a mathematical formulation to estimate the probability distribution of a species following the principle of maximum entropy, which supposes that no unfounded constraints should be included in the estimation (Phillips et al. 2006). In constructing the probability distribution, Maxent uses different types of environmental features (linear, quadratic, product, and threshold combinations of raw continuous environmental data, as well as categorical environmental data) and a regularization parameter $(\beta)$ for each feature, which estimates how close the expected value should be to the observed value (Phillips et al. 2004). For developing the model, Maxent creates random samples of background pixels $(10,000)$ from the study area as pseudoabsences. We used the default parameters throughout. The final probability distribution developed is projected onto the geographic space, and a cumulative probability (expressed as a percentage) is assigned to each pixel, interpretable as an index of suitability for the species.
Approach for modeling Argentine ant potential distribution in the Iberian Peninsula

Our approach for comparing invasion patterns in the western and eastern Iberian Peninsula consisted of two steps. (1) We selected optimal environmental datasets for modeling the species' ecological niche, and (2) we identified the areas of consensus among modeling approaches to elucidate differences and similarities between invasion patterns of the Argentine ant within the Iberian Peninsula.

To select environmental data (Step 1), we developed 50 generalized boosted models for the overall Iberian Peninsula, and for western (UTM longitude $<184,000$ ) and eastern (UTM longitude $>637,000$ ) areas separately. First, we created three occurrence datasets: 350 localities from the whole Iberian Peninsula (herein called $I b$ ), 175 localities from the western area $(w I b)$, and 142 localities from the eastern area $(e I b)$. Since true absence data were not available to calibrate models, an equal number of pseudoabsences were randomly resampled from each area. GBM then estimated the relative importance of each environmental variable in the model accounting for all the other variables. We used a permutation method, which randomly resamples each predictor variable independently and computes the associated reduction in predictive performance (Thuiller et al. 2006). However, to reduce uncertainties due to the random selection of pseudoabsence data, we developed 50 GBM models for each area using different subsets of pseudoabsence data. The influence of each predictor variable was computed by averaging its relative importance (following Friedman (2001)) across the 50 runs; the most relevant environmental variables in each area were retained, and three separate environmental data-subsets thus obtained to develop final models of Argentine ant distribution. The GBM approach averages the relative influence of each variable across all trees generated by the boosting algorithm, giving a relatively robust and stable estimate (Friedman 2001); we did not use the other approaches to estimate the relative importance of variables because we believe that this boosting approach is the most reliable and unbiased, and because comparing the choice of variables among models was not the point of the paper.

Finally (step 2), using the environmental data selected, we developed ensembles of models for 
overall, western, and eastern portions of the Iberian Peninsula. First, we divided occurrence data randomly (including presence data and an equal number of pseudoabsences) from each area into training (70\%) and testing (30\%) datasets for calibrating and testing the accuracy of models, respectively. With the training data and the previously selected environmental data, we developed models for the entire, as well as the eastern and western Iberian Peninsula areas, using GLM, GAM, GBM, GARP, and Maxent. Model performance was tested using the independent testing data set aside from model development. To reduce uncertainty caused by sampling artifacts (generated during the random resampling of presence localities and generation of pseudoabsence), we calibrated 10 replicate models for each area and modeling technique by using different combinations of training data. While presence data were selected randomly from the initial pool of Argentine ant localities, pseudoabsences were resampled each time, selecting points from the area without confirmed presence of the species.

Each set of 10 replicate models was finally transformed into a single model via a weighted model average (Eq. 1). Model weights were assigned so as to enhance contributions of those models with higher model performance values (measured by the $A U C$ of a ROC analysis) relative to the set of plausible models developed using the same modeling technique and calibration area, but based on different subsets of occurrence data, allowing us to discern differences among modeling approaches.

$$
\mathrm{g}_{\mathrm{M}}(X)=\sum_{m=1}^{10} \omega_{m} \cdot p_{m}(X) \text { where } \omega_{m}=\frac{A U C_{m}}{\sum_{m=1}^{10} A U C_{m}}
$$

where $p_{m}(x)$ is the value predicted by each replicate model $(m)$, developed applying one of the five modeling approaches and different training datasubsets; $\omega_{m}$ is the weight assigned to each replicate model taking into account its model performance, measured using the area under the curve $\left(A U C_{m}\right)$, in relation to the mean model performance of the overall set of replicate models.

However, given our interest in identifying patterns of consensus among predictions of Argentine ant distribution from different modeling techniques, we also averaged final model predictions obtained by each modeling approach. As previously showed (Eq. 1), we assigned weights depending on comparisons with the average $A U C$ of the set of replicate models for each modeling approach (see Eq. 2). This approach allowed us to identify consensus areas for Argentine ant potential distribution.

$$
\mathrm{c}(X)=\sum_{M=1}^{5} \omega_{M} \cdot g_{M}(X) \text { where } \omega_{M}=\frac{\mathrm{AUC}_{M}}{\sum_{M=1}^{5} \mathrm{AUC}_{M}}
$$

where $g_{M}(x)$ is the weighted average value for each modeling approach $(M)$ obtained using Eq. 1, and $\omega_{M}$ is the weight assigned to each averaged prediction taking into account model performance, measured as the mean area under the curve $\left(A U C_{M}\right)$ of the ten individual models developed using that particular modeling approach (Eq. 2). Finally, to identify and localize discrepancies among modeling methods in predicting potential distributions of the Argentine ant, we measured the variance among averaged predictions, which gave us greater confidence in our final results and permitted us to represent geographically uncertainties among methods (Hartley et al. 2006).

Throughout, model performance was tested using the Receiver Operating Characteristic (ROC) analysis (Hanley and McNeil 1982) implemented in R-CRAN software (function 'somers' from the 'Hmisc' library). ROC analysis evaluates model performance independently of arbitrary thresholds for presence, and has been used extensively in distribution modeling studies owing to its nonparametric thresholdindependent nature (Manel et al. 2001). Overall model performance is summarized as the area under the curve $(A U C)$, interpretable as the probability that a model discriminates correctly between presence and absence sites (Pearce and Ferrier 2000). AUC values range $0-1$, where $A U C=1$ indicates perfect model performance, and $A U C=0.5$ indicates predictive discrimination no better than random.

\section{Additional statistical analyses}

We used a repeated-measures ANOVA to assess how model performance (measured by means of $A U C$ values) varied between modeling approaches (five levels: GLM, GAM, GBM, GARP, Maxent) and areas of calibration (three levels: $I b, e I b$, and $w I b$ ), respectively. We considered modeling approaches 
and areas of calibration as fixed factors, and occurrence data-subsets used for training and testing the replicate models in each area (ten levels par area of calibration: number of iterations performed in step 2) as random factors. Repeated-measures ANOVA permitted us to deal with the non-independence in the model performance measures between predictions calibrated using the same occurrence dataset. The analysis was performed using the lme function, which performs mixed linear models, implemented in R-CRAN.

To investigate environmental relationships between eastern and western occurrence localities, we followed the methodology of Broennimann et al. (2007). A PCA analysis was conducted to visualize (in a bivariate plot of the two main factors of a PCA) variation patterns among occurrences for western and eastern areas. To search for environmental similarities/dissimilarities among ecological niches on both sides of the Iberian Peninsula, after performing a PCA analysis for eastern and western localities separately, factor coordinates of the first two principal components of each PCA were compared.

\section{Results}

Selection of environmental data

After performing a first correlation analysis, we eliminated minwtemp and EVI from the modeling exercise owing to their high correlation $(r>0.8)$ with other environmental variables. Minwtemp was highly correlated with elev and amtemp, and EVI was only correlated with $N D V I$, which is more chlorophyll-sensitive and can have a greater influence on Argentine ant distribution than EVI (Huete et al. 2002).

The averaged results of the 50 replicate GBM models identified the most relevant environmental variables, i.e. those with high values of relative influence, for predicting Argentine ant distributions in each area (Fig. 2). For Iberian-based models, the most relevant environmental variables were elev, amtemp, maxstemp, amprecip, and slope. Somewhat different results appeared when using eastern and western localities only: while western-based models also indicated NDVI as relevant, eastern-based models identified only elev, amtemp, and amprecip as relevant.
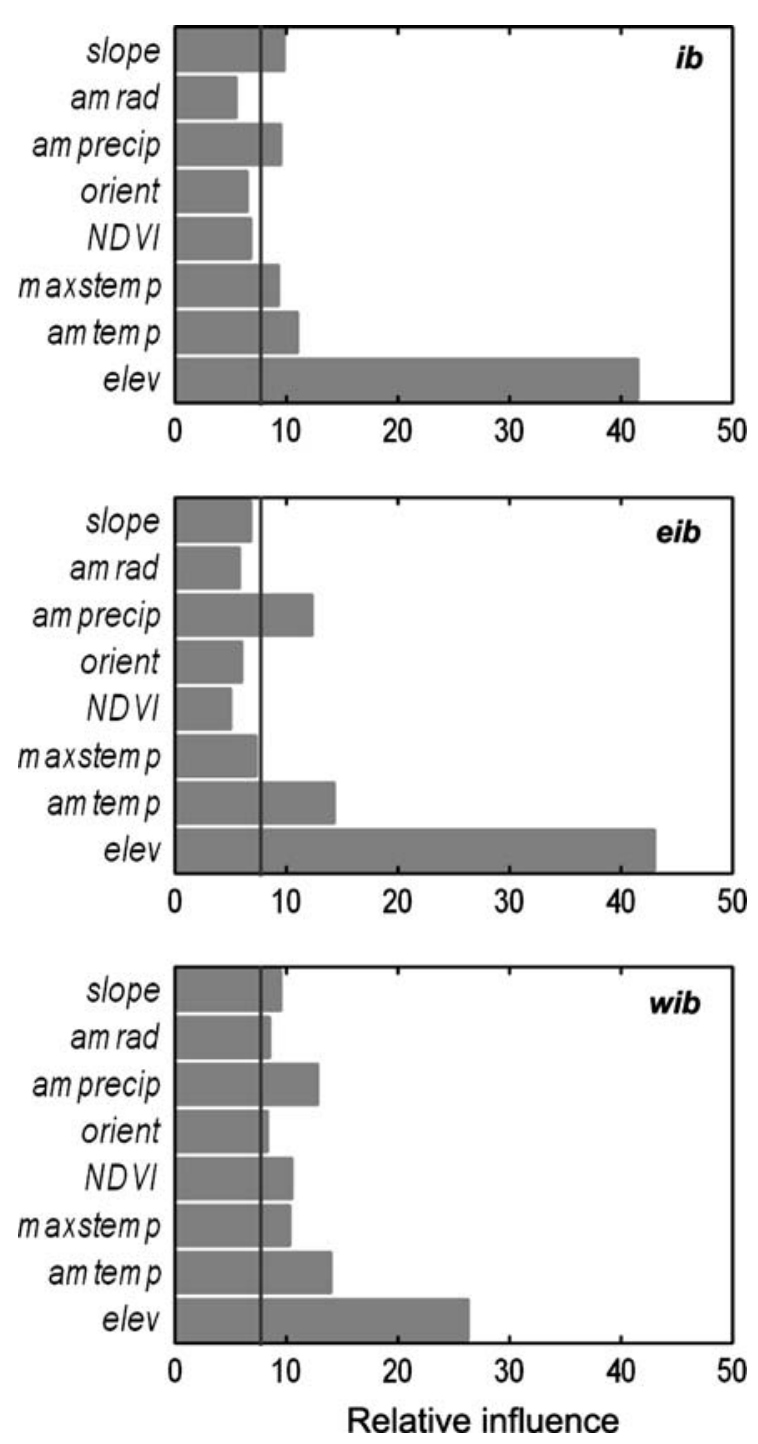

Fig. 2 Most relevant environmental variables in predicting Argentine ant distributions in areas of the overall $(I b)$, eastern $(\mathrm{e} I b)$, and western Iberian Peninsula (wIb) using generalized boosted models (step 1). Bar refers to mean relative influence of each variable developed applying the same environmental dataset to 50 different subsets of occurrences. For visualization, the dotted line indicates the threshold (relative influences $=8$ ) used to include or exclude particular variables from further analysis

Comparison between niche predictions

For modeling Argentine ant distribution across the entire peninsula, and in the eastern and western sectors separately, we developed 10-replicate models by combining the most influential variables for each region with 10 different subsets of training occurrence 
data from each area. These sets of replicate models were calibrated using different modeling techniques to reduce divergences among methods and produce ensemble predictions. The weighted average of $A U C$ values of each set of 10-replicate models ranged between 0.77 and 0.95 (mean $A U C=0.87$; Fig. 3), which indicated overall good ability to predict the distribution of the species. However, variation in predictive performance between modeling approaches was statistically significant (Table 1). Highest values of model performance were attained by Maxent models, and lowest by GARP models.

Despite these differences, all modeling methods showed similar trends in predicting Argentine ant

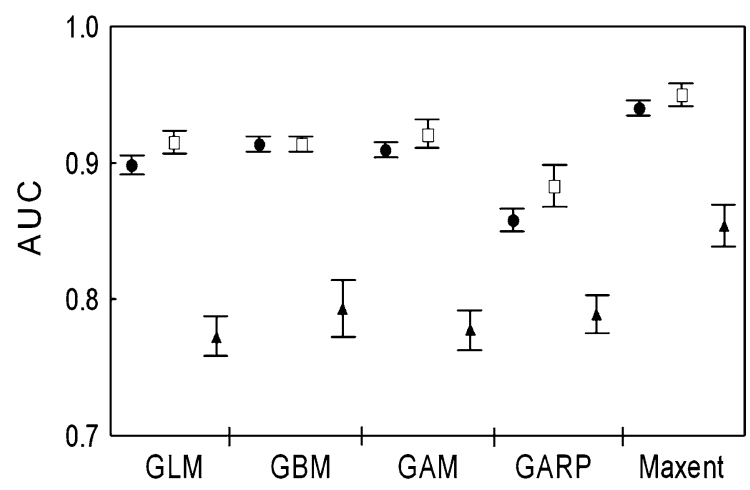

Fig. 3 Differences in model performance between modeling approaches depending on the area used for calibrating the models: overall Iberian peninsula (represented by $\mathbf{O}$ ), eastern Iberian Peninsula ( $\square$ ), western Iberian Peninsula ( $\mathbf{\Delta})$. The $y$ axis presents the mean $A U C$ value of each set of predictions developed applying the same environmental dataset to different subsets of occurrences. Whiskers show standard errors

Table 1 Repeated-measures ANOVA assessing changes in model performance between modeling approaches and areas of calibration

\begin{tabular}{llcrr}
\hline Source of variation & \multicolumn{4}{l}{ Model performance $(A U C)$} \\
\cline { 2 - 5 } & Num df & Den df & $F$-value & $P$-value \\
\hline Intercept & 1 & 116 & 23458.145 & $<0.0001$ \\
Modeling approaches & 4 & 116 & 28.780 & $<0.0001$ \\
Areas of calibration & 2 & 27 & 44.232 & $<0.0001$ \\
\hline
\end{tabular}

The analysis was performed using linear mixed effects models. Modeling approaches (five levels: GLM, GAM, GBM, GARP, Maxent) and areas of calibration (three levels: $I b, e I b$, and $w I b$ ) were included as fixed factors, and occurrence data-subsets used for training and testing the replicate models in each area (ten levels par area of calibration: number of iterations performed in step 2) as random factors distribution (Fig. 3). Models developed using occurrence data from the entire Iberian Peninsula gave $A U C$ values between 0.86 and 0.94 (mean $A U C=0.90$ ). Whereas eastern-based models gave similar $A U C$ values of $0.89-0.95$ (mean $A U C=0.92$ ), westernbased models produced lower $A U C$ values (ranging $0.77-0.85$, mean $A U C=0.80$ ). This observation was corroborated by the repeated-measures ANOVA, which found significant differences in predictive performance depending on the area: western-based models presented lower model performance than eastern or overall-based models (Table 1).

Visual comparisons of model predictions also revealed some divergences: GARP predicted the largest area suitable for Argentine ants and Maxent the narrowest areas at the highest predicted thresholds, whereas GLM, GAM, and GBM presented intermediate predicted areas (Fig. 4). However, ensemble predictions for the overall, eastern and western areas coincided in indicating coastal areas and river valleys as highly suitable for Argentine ants (Fig. 5). Nevertheless, taking into account the variability among final predictions, some areas (e.g., most river courses, and northern and southeastern coastal areas) presented high levels of variance among models.

Restricted to the initial non-correlated environmental variables, the principal component analysis aimed to describe the relationship between eastern and western localities of the Argentine ant. The first two axes of the PCA accounted for $41 \%$ of total variance: PC1 (26\% of variance) was positively correlated with NDVI $(r=0.53)$ and amprecip $(r=0.49)$, and negatively correlated with amtemp ( $r=-0.33)$; PC2 (15\% variation) was negatively correlated with maxstemp $(r=-0.58)$ and orient ( $r=-0.47$; Fig. 6). Comparisons of environmental conditions between western and eastern localities indicated some similarities, and some divergences: while occurrence data on the two sides of the Iberian Peninsula presented similar precipitation gradients, western localities seemed to occupy a larger radiation range (i.e., lower values of maxstemp and orient) than eastern localities. This pattern was confirmed by developing additional principal components analyses for each side of the Iberian Peninsula. The first factors (PC1) of each analysis were significantly correlated between areas $(r=0.95)$, but the second factors (PC2) presented a low correlation $(r=0.15)$. This result thus indicated that occurrence data of the 


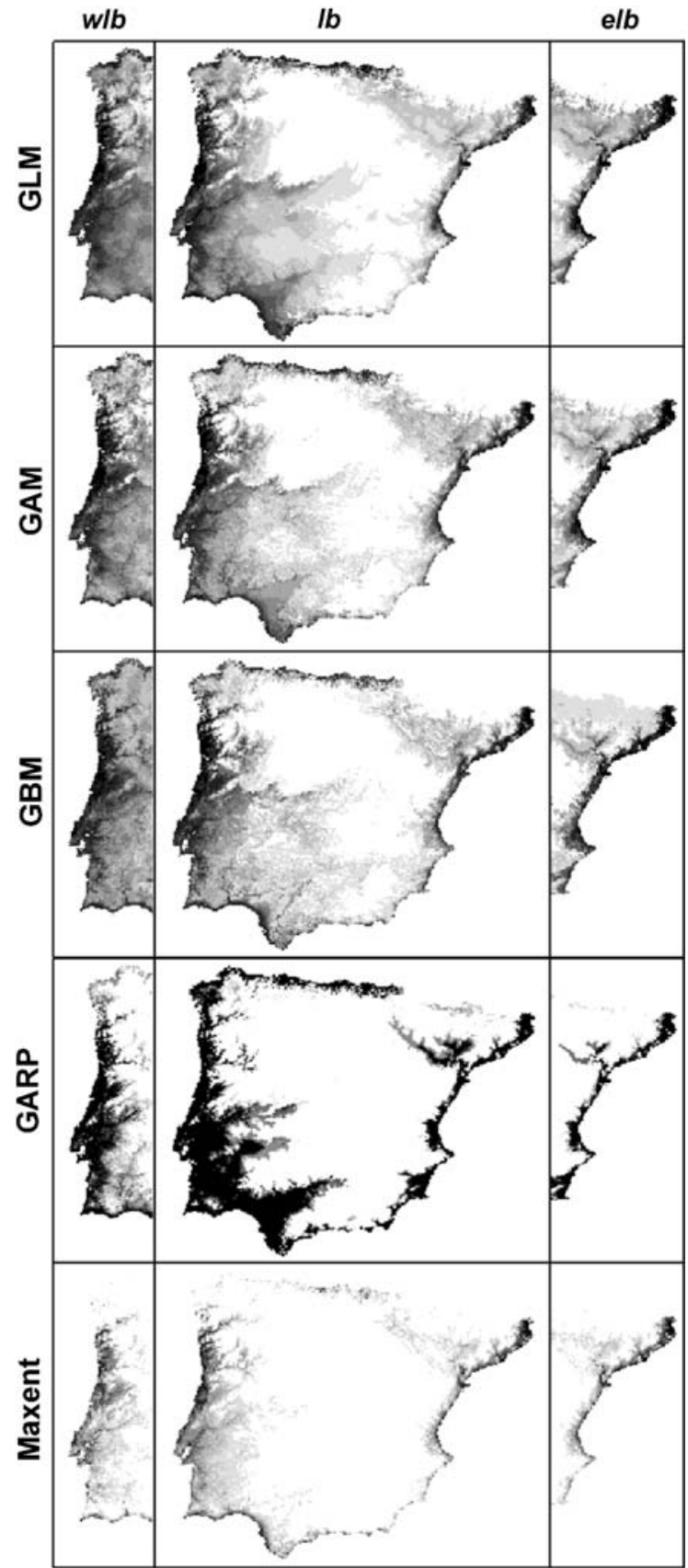

Fig. 4 Predicted potential distribution of Argentine ant in the Iberian Peninsula using different modeling approaches. Columns indicate the calibration area of the models, while rows indicate the modeling approach used: GLM, GAM, GBM, GARP, and Maxent. Note that models developed for each area were calibrated using different environmental datasets (see Results). Higher probabilities in predicting the potential geographic distribution of the Argentine ant are indicated in darker shades

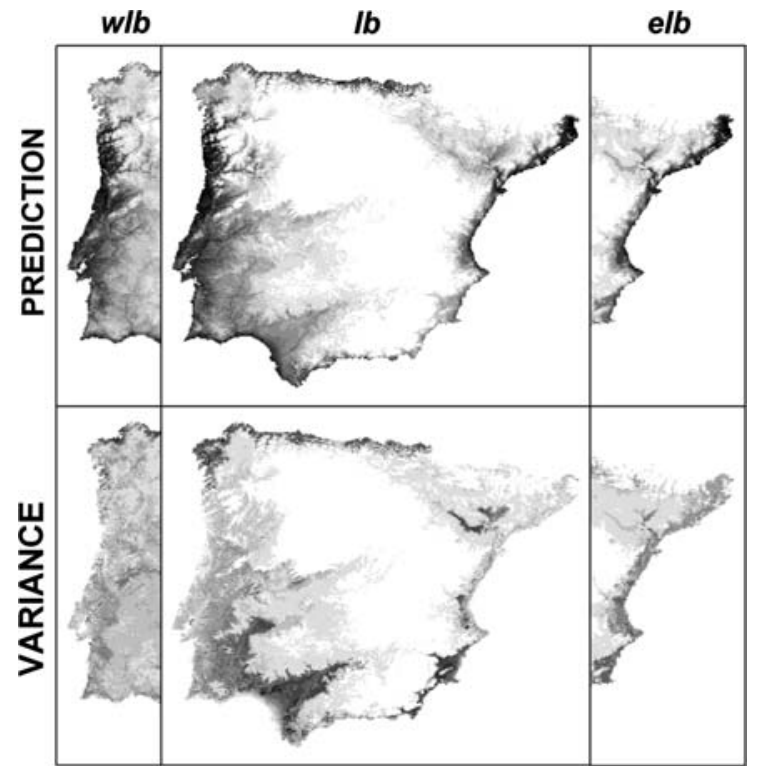

Fig. 5 Areas of consensus and variance among modeling approaches in predicting Argentine ant distribution in the Iberian Peninsula. The first row shows areas of consensus among predictions developed using GLM, GAM, GBM, GARP, and Maxent, while the second row shows the variance among them. Darker shades indicate higher agreement (first row) and higher variance (second row) between modeling approaches in predicting the potential geographic distribution of the Argentine ant

species at both sides of the Iberian Peninsula, although highly similar, are influenced in different ways by environmental conditions.

\section{Discussion}

In this exercise, we identified the most influential variables in determining Argentine ant distribution using generalized boosted models (GBM). In general, the species' distribution appears highly dependent on the shape of the elevation gradient over the entire Iberian Peninsula. However, other climatic variables (annual mean temperature and annual mean precipitation) were also important in refining our predictions. This result is consistent with our knowledge of the species, which is not known to occur in cold and dry areas of the Iberian Peninsula (Espadaler and Gómez 2003), and also with the spatial resolution of our analyses, which does not allow us to consider smallerscale processes that restrict the species' distribution 


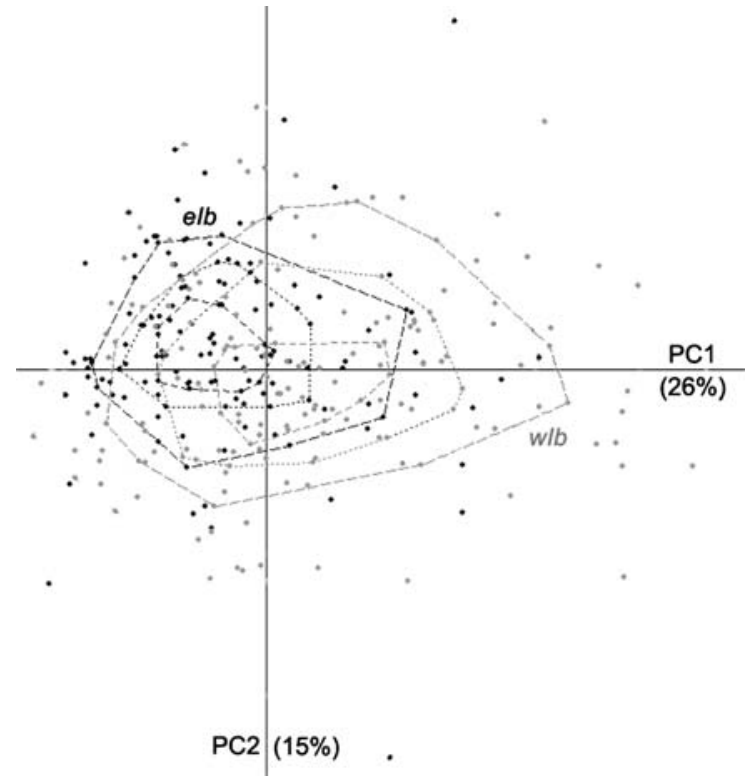

Fig. 6 Visualizations of environmental conditions of Argentine ant occurrence localities in the Iberian Peninsula in a bivariate plot of two principal components, which summarize variation among the environmental variables included in the modeling exercise. Black dots refer to occurrence data from the eastern side, while grey to western occurrences. Different lines represent the convex hulls, including $25 \%, 50 \%$ and $75 \%$ of the overall occurrences for each area

locally, such as anthropogenic disturbances or presence of watercourses (Carpintero et al. 2004; Menke and Holway 2006; Menke et al. 2007).

It is also important to notice that elevation has a stronger influence in the east than in the west, where other variables (maximum summer mean temperature, NDVI vegetation index) seem to be more influential on the species' distribution. We suspect that altitude has a lower influence in western-based models because topography is more homogeneous in the west, and it does not seem to constrain Argentine ants as much as on the eastern side, where elevations are higher. Moreover, because of Atlantic influences (lower temperatures, higher precipitation), Argentine ant distribution on the western side of the Iberian Peninsula would be more constrained by maximum summer temperature and vegetation-related variables than eastern localities. This result is supported by Way et al. (1997), who suggested that the species' distribution on the western side is constrained principally by soil type and vegetation. Contrarily, Mediterranean influences (with less precipitation and higher mean temperatures) on the eastern side restrict
Argentine ants to low elevations near the coast with temperate climates (characterized by cool temperatures and higher levels of humidity). Holway (1998) suggested that Argentine ant distribution in Mediterraean California is highly dependent on moisture levels. In dry environments, Argentine ant populations seem to be highly limited by proximity to permanent watercourses and rainfall patterns (Human et al. 1998; Menke et al. 2007; Heller et al. 2008).

Differences between the eastern and western sides of the Iberian Peninsula were expected, since models were calibrated in different areas (Van Horne 2002; Thuiller et al. 2004; Pearson et al. 2006). However, it is essential to determine whether these differences result simply from environmental differences between areas or from real ecological divergences between the two populations of Argentine ants (Roura-Pascual et al. 2006). A better knowledge of overall factors influencing the Argentine ant distribution within the Iberian Peninsula would permit to refine our predictions and establish more reliable guidelines in future management practices.

Indeed, the accuracy of our niche models in predicting Argentine ant distributions is highly dependent on the occurrence data and environmental coverages included in the analysis (Stockwell and Peterson 2002). Based on our previous experience with the same occurrence dataset, we consider the $>100$ occurrence localities to have been sufficient to predict Argentine ant distributions (Roura-Pascual et al. 2006). Moreover, the best model performance was attained using 3-6 predictor variables, which seem to be an adequate number (Peterson and Cohoon 1999). However, because these variables have been selected using only GBM, some biases enhancing the performance of this modeling approach in front of the others might have been introduced. Nevertheless, the suitability of both occurrence and environmental data seems corroborated by the high values of model performance $(A U C>0.7)$ attained in our final predictions (Fig. 3).

However, we also found slight differences between predictions depending on the method used to calibrate the model. While Maxent showed the highest model agreement between localities of Argentine ants and model predictions, GARP performed more poorly than all other methods, and GLM, GAM and GBM presented intermediate values of model performance. These results coincide generally with results of other 
comparative studies (Elith et al. 2006). However, Peterson et al. (2008) evidenced that these results are extremely biased by the evaluation technique, which favours algorithms that predict across the whole range of predicted thresholds (such as Maxent) in detriment of those models that make only predictions at the end of the spectrum (such as GARP). From a geographic point of view, these results in the model performance's value are consistent with the fact that GARP predicted broader areas as highly suitable for the species than the other methods, whereas Maxent tended to distinguished maximally among presence and absence test data and fit predictions more closely to the known distribution of the species at higher predicted thresholds. These divergences among modeling techniques, and the lack of a standardized criterion to select the most reliable prediction, suggest that conclusions based on areas of consensus can be more reliable than those derived from individual models developed via a single modeling approach. In addition, the use of consensual predictions allows identifying areas of disagreement between modeling approaches. More than simple artifacts, these discrepancies indicate regions where the invasive potential of the species is not well understood, and where studies should be conducted to refine our knowledge of the biological invasion (Hartley et al. 2006). However, further refinements of the process (principally in relation to the environmental data selection, and the implementation of the weighting scheme) should be developed to produce an objective framework in which to conduct consensual modeling approaches. The advantage of using consensual models is that they incorporate most of the uncertainties into the picture (Thuiller 2004; Araújo and New 2007). This is especially important in this study, where models calibrated using only records from the invaded range might underestimate the potential range of the species (Welk 2004).

Given the current distribution of the Argentine ant, predictions of its potential ensemble distribution across the Iberian Peninsula suggest that a further expansion of the species is possible along the coast and into inland areas along river valleys. Mountain ranges and inland plateau are predicted as highly unsuitable for Argentine ants. Since river courses make it easy for the species to enter far inland, scrutiny efforts should focus along the Ebro, Guadalquivir, Guadiana, Tagus, Douro, and Minho river valleys to look after future expansions into the interior of the Iberian Peninsula. Moreover, although northern and southeastern coasts also appear suitable for the Argentine ant, further research is necessary to determine the species' real distribution in these areas where model predictions are variable. Expansion of the invasion along the Cantabric coast is probably limited by lower temperatures, but on the Betic Systems coast by higher temperatures and extreme drier conditions. Special attention should also be paid at some interior areas of the Guadiana, Guadalquivir and Ebro depressions, where variance among model predictions is high. In these interior areas, L. humile will probably be limited to moist areas or along watercourses (Holway 1995; Human et al. 1998).

Nevertheless, to size up whether herein developed models are underestimating the species' potential distribution or not, we compared our predictions (Fig. 5) with those predictions obtained in RouraPascual et al. (2006) using occurrences from both native and invaded ranges to determine the ecological niche of the Argentine ant in the Iberian Peninsula. Both studies used the same set of occurrence data from the invaded range and similar spatial scales, but slightly different environmental data and modeling approaches. In general, invaded-based predictions from both studies indicate coastal areas and major rivers as highly suitable for the species. However, when compared with native-based models in RouraPascual et al. (2006), predictions developed in this study might underestimate the suitability of inland plateaus for Argentine ants and overestimate the capacity of the species to occupy northern coastal areas. In fact, the Cantabric Coast was already identified as a highly uncertain region by ensemble predictions (Fig. 5). Contrarily, although potential ensemble distributions were also highly variable in river valley depressions, native-based models seem to corroborate the vulnerability of these areas to become invaded by the Argentine ant. Especially important are the Guadalquivir and Ebro depressions, where native-based models predict high values of suitable for the species.

Additionally, comparing ensemble predictions for western and eastern areas derived from models calibrated using occurrences from each area separately with predictions calibrated using occurrences from the overall Iberian Peninsula (i.e. using a wider range of environmental characteristics), differences are small. As in other studies (Peterson et al. 1999), 
these results indicate that Argentine ant populations on the two sides of the Iberian Peninsula occupy similar ecological conditions and, therefore, present similar ecological niches. This idea is corroborated by the PCA analyses, which indicate that environmental characteristics of Argentine ant localities at western and eastern Iberian Peninsula are correlated.

The small divergences observed between predictions could be simply sampling artifacts or may reflect slight differences in the species' ecological niche (Broennimann et al. 2007). Real ecological niche differences between western and eastern populations, not due to modeling artifacts (Roura-Pascual et al. 2006), could result from different origins of introduced populations, as the existence of two supercolonies of the Argentine ant seems to indicate (Giraud et al. 2002). The eastern supercolony (so-called Catalan colony) is differentiated from the main supercolony that is spread more broadly in the Peninsula (Giraud et al. 2002). However, since the first reference to Argentine ant occurrence in the Iberian Peninsula was earlier on the western side (1894 in Oporto) than on the eastern side (1923 in Valencia, probably 1919; Espadaler and Gómez 2003), and the so-called Catalan colony is restricted to the northeastern side of the Iberian Peninsula, we cannot conclude with certainty that these slight divergences reflect real ecological niche differences. Contrarily, these divergences may be the results of the invasion history and/or environmental differences between both sides of the Iberian Peninsula (Roura-Pascual et al. 2006).

\section{Conclusions}

This modeling exercise attempts to understand factors responsible for shaping Argentine ant distributions in the Iberian Peninsula, and to identify the areas most vulnerable to be invaded by the species. However, given its anthropophilic tendency and opportunistic requirements for propagule pressure (Hee et al. 2000), Argentine ant expansion is expected to occur mostly in populated areas (especially coastal areas and river valleys) of the Iberian Peninsula, where opportunities to control invasions effectively are few. In this sense, although screening areas suitable for the species cannot provide a basis for establishing preventive guidelines for the overall Peninsula, it can help to plan local measures in areas where Argentine ants cause problems to humans (e.g., building infestations) or natural ecosystems (e.g., threaten biodiversity or ecosystem functioning; Passera 1994).

In this sense, our results indicate that Argentine ants still have potential for further expansions in the Iberian Peninsula, especially along coastal areas and watercourses. Argentine ant distributions seem to be influenced principally by altitude, mean temperature, and precipitation. However, future studies should aim to characterize the suitable range for the species at local scales. Special attention should be focus on areas of maximum incertitude among models, to elucidate the ultimate drivers of the species' distribution. On the other hand, although our results suggest that different populations of Argentine ant within the Iberian Peninsula present similar ecological niches, more specific studies of ecological divergences of populations are necessary to improve niche predictions and identify areas environmentally resistant to invasion.

Finally, from the methodological point of view, use of ensemble predictions to identify the potential distributional areas of invasive species provided new insights into the development of an objective framework on consensus modeling. Future studies of methods for selecting environmental data and selecting weighting schemes would permit more objective, consensus-based predictions.

Acknowledgments Special thanks to P. Pons, C. Gómez and E. Knox-Davis for their comments on the manuscript, and M. Clavero, S. Phillips, and J. Hortal for statistical guidance. $\mathrm{X}$. Espadaler provided useful comments on historical data of the Argentine ant invasion in the Iberian Peninsula. This research was funded by the Ministry of Education and Science CGL200405240-C02-02/BOS and MEC/FEDER2007-64080-C02-02/ BOS of the Spanish Government in support of N. RouraPascual, and is a contribution to the European Research Group GDRE "Mediterranean and mountain systems in a changing world". N. Roura-Pascual benefited from a Beatriu de Pinós postdoctoral grant (2006 BP-A 10124) from Catalan Agency for Management of University and Research Grants, and L. Brotons from a Ramon y Cajal contract from the Spanish government. W. Thuiller was partly funded by the EU FP6 MACIS specific targeted project (Minimisation of and Adaptation to Climate change: Impacts on biodiversity $\mathrm{N}^{\circ}$ 044399) and EU FP6 ECOCHANGE integrated project (Challenges in assessing and forecasting biodiversity and ecosystem changes in Europe).

\section{References}

Abril S (2005) Ecologia alimentària de la formiga argentina (Linepithema humile) en ecosistemes naturals: activitat 
d'extracció de melassa de Quercus suber i dieta sòlida. Universitat de Girona, Dissertation

Akaike H (1974) A new look at the statistical model identification. IEEE Trans Automat Contr 19:716-723. doi: 10.1109/TAC.1974.1100705

Anderson RP, Lew D, Peterson AT (2003) Evaluating predictive models of species' distributions: criteria for selecting optimal models. Ecol Model 162:211-232. doi:10.1016/ S0304-3800(02)00349-6

Araújo MB, Guisan A (2006) Five (or so) challenges for species distribution modelling. J Biogeogr 33:1677-1688. doi:10.1111/j.1365-2699.2006.01584.x

Araújo MB, New M (2007) Ensemble forecasting of species distributions. Trends Ecol Evol 22:42-47. doi:10.1016/j. tree.2006.09.010

Araújo MB, Thuiller W, Pearson RG (2006) Climate warming and the decline of amphibians and reptiles in Europe. $\mathrm{J}$ Biogeogr 33:1712-1728. doi:10.1111/j.1365-2699.2006. 01482.x

Breiman L, Friedman JH, Olshen RA et al (1984) Classification and regression trees. Chapman and Hall, New York

Broennimann O, Treier UA, Muller-Scharer H et al (2007) Evidence of climatic niche shift during biological invasion. Ecol Lett 10:701-709. doi:10.1111/j.1461-0248. 2007.01060.x

Brotons L, Thuiller W, Araújo MB et al (2004) Presenceabsence versus presence-only modelling methods for predicting bird habitat suitability. Ecography 27:437-448. doi:10.1111/j.0906-7590.2004.03764.x

Carpintero S, Reyes-López J (2008) The role of competitive dominance in the invasive ability of the Argentine ant (Linepithema humile). Biol Invasions 10:25-35

Carpintero S, Reyes-López J, Arias de Reyna L (2004) Impact of human dwellings on the distribution of the exotic Argentine ant: a case study in the Doñana National Park, Spain. Biol Conserv 115:279-289. doi:10.1016/S00063207(03)00147-2

Carpintero S, Reyes-López J, Arias de Reyna L (2005) Impact of Argentine ants (Linepithema humile) on an arboreal ant community in Doñana National Park, Spain. Biodivers Conserv 14:151-163. doi:10.1007/s10531-005-3947-6

Casellas D (2004) Tasa de expansión de la hormiga argentina, Linepithema humile (Mayr 1868), (Hymenoptera, Dolichoderine) en un área mediterránea. Bol Asoc Esp Entomol 28:207-216

Chapin FSI, Zavaleta ES, Eviner VT et al (2000) Consequences of changing biodiversity. Nature 405:234-242. doi: $10.1038 / 35012241$

Drake JM, Lodge DM (2006) Forecasting potential distributions of nonindigenous species with a genetic algorithm. Fisheries 31:9-16. doi:10.1577/1548-8446(2006)31 [9:FPDONS]2.0.CO;2

Elith J, Graham CH, Anderson RP et al (2006) Novel methods improve prediction of species' distributions from occurrence data. Ecography 29:129-151. doi:10.1111/j.2006. 0906-7590.04596.x

Elith J, Leathwick JR, Hastie T (2008) A working guide to boosted regression trees. J Anim Ecol 77:802-813. doi: 10.1111/j.1365-2656.2008.01390.x

Espadaler X, Gómez C (2003) The Argentine ant, Linepithema humile, in the Iberian Peninsula. Sociobiology 42:187-192
Farina A, Bogaert J, Schipani I (2005) Cognitive landscape and information: new perspectives to investigate the ecological complexity. Biosystems 79:235-240. doi:10.1016/j. biosystems.2004.09.018

Friedman JH (2001) Greedy function approximation: A gradient boosting machine. Ann Stat 29:1189-1232. doi: 10.1214/aos/1013203451

Friedman JH, Meulman JJ (2003) Multiple additive regression trees with application in epidemiology. Stat Med 22:1365-1381

Giraud T, Pedersen JS, Keller L (2002) Evolution of supercolonies: the Argentine ants of southern Europe. Proc Natl Acad Sci USA 99:6075-6079. doi:10.1073/pnas.092694199

Grinnell J (1917) Field tests of theories concerning distributional control. Am Nat 51:115-128. doi:10.1086/279591

Guisan A, Thuiller W (2005) Predicting species distribution: offering more than simple habitat models. Ecol Lett 8:993-1009. doi:10.1111/j.1461-0248.2005.00792.x

Guisan A, Edwards TC, Hastie T (2002) Generalized linear and generalized additive models in studies of species distributions: setting the scene. Ecol Model 157:89-100. doi: 10.1016/S0304-3800(02)00204-1

Hanley JA, McNeil BJ (1982) The meaning and use of the area under a receiver operating characteristic (ROC) Curve. Radiology 143:29-36

Hartley S, Lester PJ (2003) Temperature-dependent development of the Argentine ant, Linepithema humile (Mayr) (Hymenoptera: Formicidae): a degree-day model with implications for range limits in New Zealand. NZ Entomol 26:91-100

Hartley S, Harris R, Lester PJ (2006) Quantifying uncertainty in the potential distribution of an invasive species: climate and the Argentine ant. Ecol Lett 9:1068-1079. doi: 10.1111/j.1461-0248.2006.00954.x

Hastie TJ, Tibshirani RJ (1990) Generalized additive models. Chapman \& Hall, London

Hee JJ, Holway DA, Suarez AV et al (2000) Role of propagule size in the success of incipient colonies of the invasive Argentine ant. Conserv Biol 14:559-563. doi:10.1046/j. 1523-1739.2000.99040.x

Heller NE, Sanders NJ, Gordon DM (2006) Linking temporal and spatial scales in the study of an Argentine ant invasion. Biol Invasions 8:501-507. doi:10.1007/s10530005-6411-3

Heller NE, Sanders NJ, Shors JW et al (2008) Rainfall facilitates the spread, and time alters the impact, of the invasive Argentine ant. Oecologia 155:385-395. doi:10.1007/ s00442-007-0911-z

Holway DA (1995) Distribution of the Argentine ant (Linepithema humile) in Northern California. Conserv Biol 9:1634-1637. doi:10.1046/j.1523-1739.1995.09061634.x

Holway DA (1998) Factors governing rate of invasion: a natural experiment using Argentine ants. Oecologia 115:206-212. doi:10.1007/s004420050509

Holway DA, Suarez AV, Case TJ (2002) Role of abiotic factors in governing susceptibility to invasion: a test with Argentine ants. Ecology 83:1610-1619

Huete A, Didan K, Miura R et al (2002) Overview of the radiometric and biophysical performance of the MODIS vegetation indices. Remote Sens Environ 83:195-213. doi:10.1016/S0034-4257(02)00096-2 
Human KG, Weiss S, Weiss A et al (1998) Effects of abiotic factors on the distribution and activity of the invasive Argentine ant (Hymenoptera: Formicidae). Environ Entomol 27:822-833

Hutchinson GE (1957) A treatise on limnology. Wiley, New York

Justice C, Vermote E, Townshend JRG et al (1998) The moderate resolution imaging spectroradiometer (MODIS): land remote sensing for global change research. IEEE Trans Geosci Rem Sens 36:1228-1249. doi:10.1109/ 36.701075

Krushelnycky PD, Joe SM, Medeiros AC et al (2005) The role of abiotic conditions in shaping the long-term patterns of a high-elevation Argentine ant invasion. Divers Distrib 11:319-331. doi:10.1111/j.1366-9516.2005.00151.x

Leathwick JR, Elith J, Francis MP et al (2006) Variation in demersal fish species richness in the oceans surrounding New Zealand: an analysis using boosted regression trees. Mar Ecol Prog Ser 321:267-281. doi:10.3354/meps321267

Mack MC, Simberloff D, Lonsdale WM et al (2000) Biotic invasions: causes, epidemiology, global consequences, and control. Ecol Appl 10:689-710. doi:10.1890/10510761(2000)010[0689:BICEGC]2.0.CO;2

Mackey BG, Lindenmayer DB (2001) Towards a hierarchical framework for modelling the spatial distribution of animals. J Biogeogr 28:1147-1166. doi:10.1046/j.13652699.2001.00626.x

Manel S, Williams HC, Ormerod SJ (2001) Evaluating presence-absence models in ecology: the need to account for prevalence. J Appl Ecol 38:921-931. doi:10.1046/j.13652664.2001.00647.x

Menke SB, Holway DA (2006) Abiotic factors control invasion by Argentine ants at the community scale. J Anim Ecol 75:368-376. doi:10.1111/j.1365-2656.2006.01056.x

Menke SB, Fisher RN, Jetz W et al (2007) Biotic and abiotic controls of Argentine ant invasion success at local and landscape scales. Ecology 88:3164-3173. doi:10.1890/070122.1

Ninyerola M, Pons X, Roure JM (2005) Atlas climático digital de la Península Ibérica: metodología y aplicaciones en bioclimatología y geobotánica. Universidad Autónoma de Barcelona

Passera L (1994) Characteristics of tramp species. In: Williams DF (ed) Exotic ants. Biology, impact, and control of introduced species. Westview Press, Boulder

Pearce JL, Boyce MS (2006) Modelling distribution and abundance with presence-only data. J Appl Ecol 43:405412. doi:10.1111/j.1365-2664.2005.01112.x

Pearce J, Ferrier S (2000) Evaluating the predictive performance of habitat models developed using logistic regression. Ecol Model 133:225-245. doi:10.1016/S03043800(00)00322-7

Pearson RG, Thuiller W, Araújo MB et al (2006) Model-based uncertainty in species range prediction. J Biogeogr 33:1704-1711. doi:10.1111/j.1365-2699.2006.01460.x

Peterson AT (2003) Predicting the geography of species' invasions via ecological niche modeling. Q Rev Biol 78:21-35. doi:10.1086/378926

Peterson AT, Cohoon KP (1999) Sensitivity of distributional prediction algorithms to geographic data completeness.
Ecol Model 117:159-164. doi:10.1016/S0304-3800(99) 00023-X

Peterson AT, Soberón J, Sánchez-Cordero V (1999) Conservatism of ecological niches in evolutionary time. Science 285:1265-1267. doi:10.1126/science.285.5431.1265

Peterson AT, Papeş M, Soberón J (2008) Rethinking receiver operating characteristic analysis applications in ecological niche modelling. Ecol Model 213:63-72

Phillips SJ, Dudík M, Schapire RE (2004) A maximum entropy approach to species distribution modeling. In: Proceedings of the 21st international conference on machine learning, Banff, Canada, pp 655-662

Phillips SJ, Anderson RP, Schapire RE (2006) Maximum entropy modeling of species geographic distributions. Ecol Model 190:231-259. doi:10.1016/j.ecolmodel.2005. 03.026

Ridgeway G (1999) The state of boosting. Comput Sci Stat 31:172-181

Rouget M, Richardson DM, Lavorel S et al (2001) Determinants of distribution of six Pinus species in Catalonia, Spain. J Veg Sci 12:491-502. doi:10.2307/3237001

Roura-Pascual N, Suarez AV, Gómez C et al (2004) Geographical potential of Argentine ants (Linepithema humile Mayr) in the face of global climate change. Proc R Soc Lond B Biol Sci 271:2527-2535. doi:10.1098/rspb.2004. 2898

Roura-Pascual N, Suarez AV, McNyset K et al (2006) Niche differentiation and fine-scale projections for Argentine ants based on remotely sensed data. Ecol Appl 16:18321841. doi:10.1890/1051-0761(2006)016[1832:NDAFPF] 2.0.CO;2

Rushton SP, Ormerod SJ, Kerby G (2004) New paradigms for modelling species distributions? J Appl Ecol 41:193-200. doi:10.1111/j.0021-8901.2004.00903.x

Soberón J, Peterson AT (2005) Interpretation of models of fundamental ecological niches and species' distributional areas. Biodivers Inform 2:1-10

Stockwell DRB, Noble IR (1992) Induction of sets of rules from animal distribution data: a robust and informative method of data analysis. Math Comput Simul 33:385-390. doi:10.1016/0378-4754(92)90126-2

Stockwell DRB, Peters D (1999) The GARP modelling system: problems and solutions to automated spatial prediction. Int J Geogr Inf Sci 13:143-158. doi:10.1080/ 136588199241391

Stockwell DRB, Peterson AT (2002) Controlling bias in biodiversity data. In: Scott JM, Heglund PJ, Morrison ML et al (eds) Predicting species occurrences: issues of accuracy and scale. Island Press, Washington, pp 537-546

Suarez AV, Holway DA, Case TJ (2001) Patterns of spread in biological invasions dominated by long-distance jump dispersal: insights from Argentine ants. Proc Natl Acad Sci USA 98:1095-1100. doi:10.1073/pnas.98.3.1095

Thuiller W (2003) BIOMOD - optimizing predictions of species distributions and projecting potential future shifts under global change. Glob Change Biol 9:1353-1362. doi: 10.1046/j.1365-2486.2003.00666.x

Thuiller W (2004) Patterns and uncertainties of species' range shifts under climate change. Glob Change Biol 10:2020 2027. doi:10.1111/j.1365-2486.2004.00859.x 
Thuiller W, Vayreda J, Pino J et al (2003) Large-scale environmental correlates of forest tree distributions in Catalonia (NE Spain). Glob Ecol Biogeogr 12:313-325. doi:10.1046/j.1466-822X.2003.00033.x

Thuiller W, Brotons L, Araújo MB et al (2004) Effects of restricting environmental range of data to project current and future species distributions. Ecography 27:165-172. doi:10.1111/j.0906-7590.2004.03673.x

Thuiller W, Midgley GF, Rouget M et al (2006) Predicting patterns of plant species richness in megadiverse South Africa. Ecography 29:733-744. doi:10.1111/j.09067590.2006.04674.x

Tsutsui ND, Suarez AV, Holway DA et al (2001) Relationships among native and introduced populations of the Argentine ant (Linepithema humile) and the source of introduced populations. Mol Ecol 10:2151-2161. doi:10.1046/j.09621083.2001.01363.x

Van Horne B (2002) Approaches to habitat modeling: the tensions between pattern and process and between specificity and generality. In: Scott JM, Heglund, PJ, Morrison ML et al (eds) Predicting species occurrences: issues of accuracy and scale. Island Press, Washington, pp 63-72

Vega SJ, Rust MK (2001) The Argentine ant - a significant invasive species in agricultural, urban and natural environments. Sociobiology 37:3-25
Vitousek PM, D’Antonio CM, Loope LL et al (1997) Introduced species: a significant component of human-caused global change. N Z J Ecol 21:1-16

Ward DF (2007) Modelling the potential geographic distribution of invasive ant species in New Zealand. Biol Invasions 9:723-735. doi:10.1007/s10530-006-9072-y

Ward DF, Harris RJ, Stanley MC (2005) Human-mediated range expansion of Argentine ants Linepithema humile (Hymenoptera: Formicidae) in New Zealand. Sociobiology 45:401-407

Way MJ, Cammell ME, Paiva MR et al (1997) Distribution and dynamics of the Argentine ant Linepithema (Iridomyrmex) humile (Mayr) in relation to vegetation, soil conditions, topography and native competitor ants in Portugal. Insect Soc 44:415-433

Welk E (2004) Constraints in range predictions of invasive plant species due to non-equilibrium distribution patterns: purple loosestrife (Lythrum salicaria) in North America. Ecol Model 179:551-567. doi:10.1016/j.ecolmodel.2004. 04.020

Wiens JA (1989) Spatial scaling in ecology. Funct Ecol 3:385397. doi: $10.2307 / 2389612$

Wild AL (2004) Taxonomy and distribution of the Argentine ant, Linepithema humile (Hymenoptera: Formicidae). Ann Entomol Soc Am 97:1204-1215. doi:10.1603/0013-8746 (2004)097[1204:TADOTA]2.0.CO;2 